\title{
Preliminary Results on the Daily and Seasonal Rhythms of Cuttlefish Sepia officinalis (Linnaeus, 1758) Locomotor Activity in Captivity
}

\author{
Catarina C.V. Oliveira 1,* (D), Mayra I. Grano-Maldonado ${ }^{1}$ (D), Rui A. Gonçalves ${ }^{1,2}$ (D), \\ Paulo A. Frias ${ }^{1,3}$ and António V. Sykes ${ }^{1}$ \\ 1 CCMAR_Centro de Ciências do Mar, Universidade do Algarve, 8005-139 Faro, Portugal; \\ grano_mayra@hotmail.com (M.I.G.-M.); ralexandr3@gmail.com (R.A.G.); pfrias82@gmail.com (P.A.F.); \\ asykes@ualg.pt (A.V.S.) \\ 2 Biomin Holding $\mathrm{GmbH}$, Erber Campus 1, 3131 Getzersdorf, Austria \\ 3 MARE-Marine and Environmental Sciences Centre, ISPA-Instituto Universitário, Rua Jardim do Tabaco, \\ 34, 1149-041 Lisboa, Portugal \\ * Correspondence: ccoliveira@ualg.pt; Tel.: +351-289-800-051
}

Academic Editor: Maria Ángeles Esteban

Received: 7 June 2017; Accepted: 23 June 2017; Published: 28 June 2017

\begin{abstract}
This research was aimed at characterizing the daily rhythms of locomotor activity of cuttlefish Sepia officinalis (Linnaeus, 1758), a promising aquaculture species, in a captive environment. Cuttlefish were distributed within two tanks equipped with infrared photocells, allowing the monitoring of locomotor activity continuously from August to February. Results showed a preference of cuttlefish for being active during the night in summer $\left(24.2 \pm 1.3{ }^{\circ} \mathrm{C}\right)$ and in autumn $\left(18.4 \pm 3.4^{\circ} \mathrm{C}\right)$, with maximum activity peaks observed, respectively, at 01:09 $\mathrm{h}$ and 21:47 $\mathrm{h}$, in close relation with sunset time. In winter $\left(12.7 \pm 1.4^{\circ} \mathrm{C}\right)$, this preference changed, with higher levels of activity observed during the afternoon in December (15:20 h) and in January (18:13 h), thus suggesting this species as possessing a dualistic behaviour. Levels of activity progressively decreased during autumn and winter, likely related to low temperatures. The present study offers new insights on the behaviour of Sepia officinalis, presenting a variability of patterns across seasons, regulated by environmental synchronizers; photoperiod determining the activity periods, and temperature modulating the levels of activity. Such information may be a valuable tool for the improvement of cuttlefish culture protocols in aquaculture, and consequently its welfare.
\end{abstract}

Keywords: behaviour; cephalopod; cuttlefish; daily rhythms; environmental synchronizers; photoperiod

\section{Introduction}

Cephalopods are considered as an alternate group for aquaculture species diversification [1,2], not only because they are a good food source (highly appreciated in some worldwide markets, e.g., Portugal, Spain, Italy and Asia) and have the potential to quickly reach a market size, but also because they are considered animal models in several fields of research [3-5], and it is expected that such models are progressively obtained from bioteriums instead of being captured from nature.

Despite the recent advances in culture protocols of several cephalopod species [2], there is still little information available about the biological rhythms of cephalopods in captivity. In fact, to the best of our knowledge, there are only 4 published papers concerning this theme, and these are focused on octopus species [6-9]. This issue assumes increasing importance with the enforcement of EU welfare legislation (Directive 2010/63/EU), and this information is critical for the future update of Annex III (housing conditions) for cephalopods of that Directive, and for a future update of the Guidelines 
for the Care and Welfare of Cephalopods in Research [10]. If it is considered that the European cuttlefish Sepia officinalis (Linnaeus, 1758) may have, at the least, two different sleep-like states [11], the importance of this study becomes even more evident.

Chronobiology is the field of science that examines periodic phenomena in living organisms and the mechanisms of synchronization with the natural cycles of the environment [12]. In anticipation of the cyclic changes in photoperiod and temperature [13,14], animals choose the most suitable moment to feed, reproduce or be active, thereby optimizing their biological processes $[15,16]$. Biological rhythms are classified as daily rhythms when the oscillation periodicity is around $24 \mathrm{~h}$, and called circadian when the rhythm persists and freely runs under constant environmental conditions, proving their endogenous origin $[17,18]$. In teleost fish, each species shows daily patterns of locomotor activity that can go from diurnal and nocturnal, to crepuscular, or a combination of these. In some cases, within the same species, different individuals can show a great variability in their daily activity patterns [19]. In contrast to cephalopods, in the last two decades several studies have focused on the study of daily and circadian rhythms in teleosts, namely their behavioural and neuroendocrine rhythms $[15,16,20]$. A better knowledge of the circadian system is essential for the domestication of targeted species for aquaculture (cephalopods included) and for the optimization of existing production protocols.

In nature, cuttlefish are reported as being essentially crepuscular or nocturnal, although they may be active during daytime [21,22]. These authors revealed much about their reproductive biology, foraging behaviours, etc., but only in the natural habitat. Therefore, the aim of this research was to perform a first characterisation of the daily and seasonal behavioural rhythms of cuttlefish in captivity, by monitoring locomotor activity under natural conditions of temperature and photoperiod.

\section{Results and Discussion}

The mean cumulative mortality of both tanks is shown in Figure 1. Animals started dying after maturity, and due to normal senescence, from the beginning of December 2011 onwards.

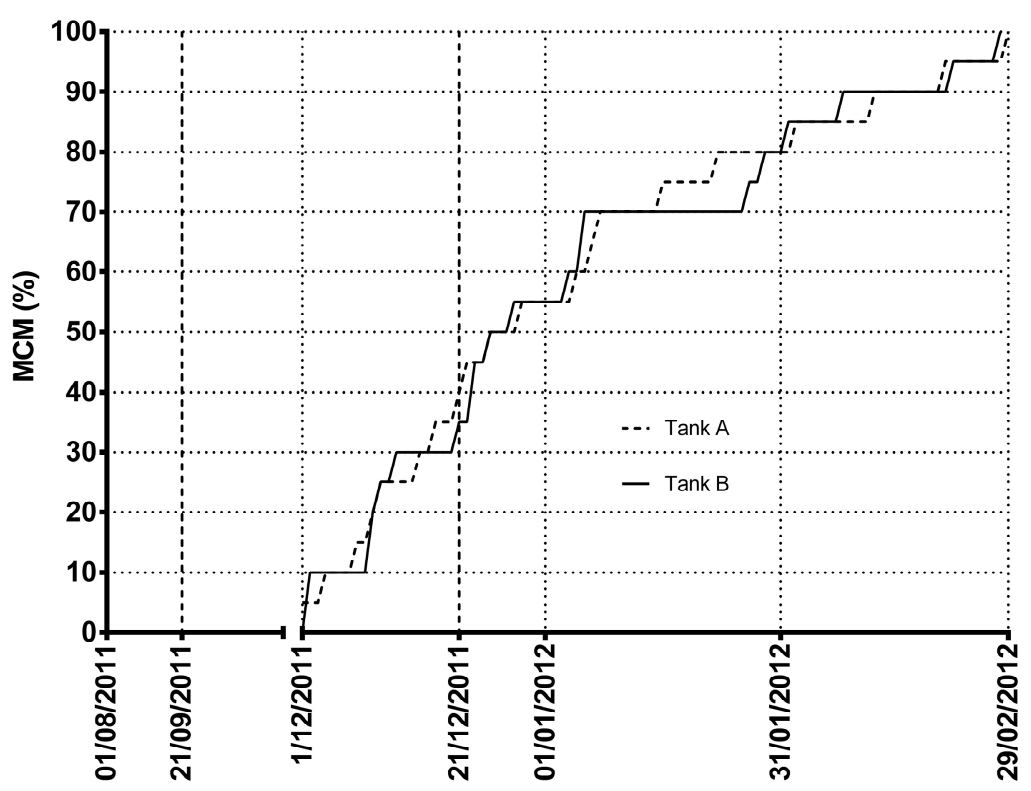

Figure 1. Mean cumulative mortality (MCM, \%) of both cuttlefish stocks through the different seasons (bold vertical dash lines) and sets (vertical dash lines) used for studying the biological rhythms of the cuttlefish S. officinalis.

Cuttlefish displayed many behavioural variations during the seven-month duration of the study, with three different patterns identified, corresponding to the different seasons (summer, autumn and winter). In summer, when seawater temperature averaged around $24.2 \pm 1.3^{\circ} \mathrm{C}$ (Figure 2), the 
activity was intense and markedly nocturnal (Figure 3a). The activity occurred predominantly after sunset $(68.29 \% ; p<0.0001$; Figure $3 b)$, with some minor occurrences during daytime (mean values of $2.33 \pm 1.26$ vs. $5.92 \pm 0.80$ counts $/ 10 \mathrm{~min}$, respectively for day and night periods), namely at feeding times.

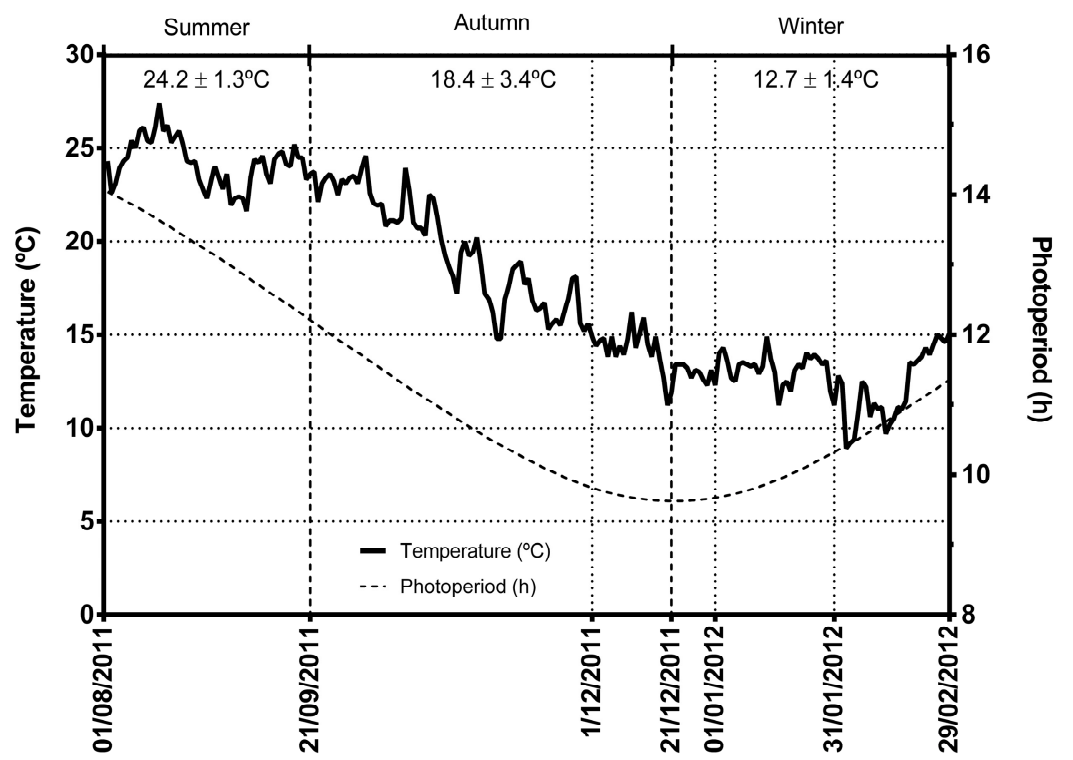

Figure 2. Temperature $\left({ }^{\circ} \mathrm{C}\right.$ ) and photoperiod (hours of light) through the different seasons (bold vertical dash lines) and sets (vertical dash lines) used for studying the biological rhythms of the cuttlefish Sepia officinalis.

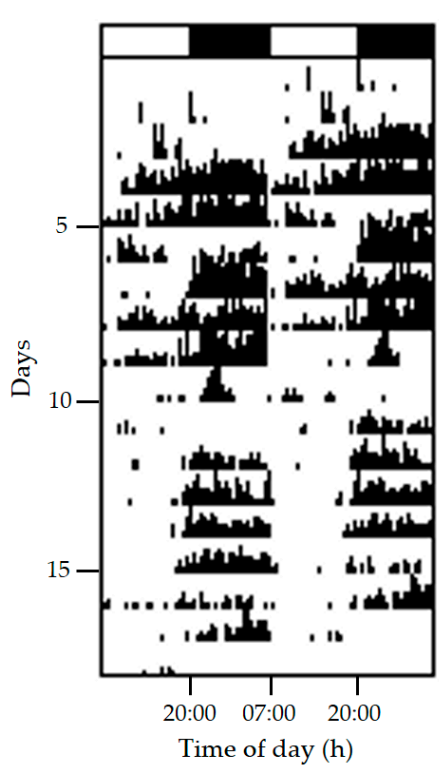

(a)

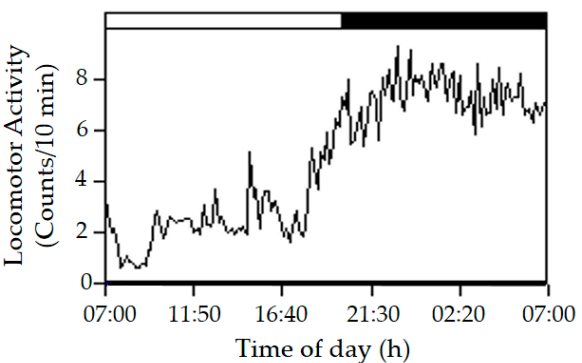

(b)

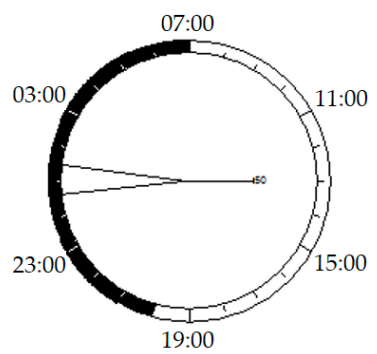

(c)

Figure 3. Representative actogram of locomotor activity of cuttlefish reared under natural conditions of photoperiod (13:11 Light:Dark), registered during summer (a) and respective mean waveform (b) and polar representation of the COSINOR analysis, depicting clockwise the daily cycle of activity (c). The white and black bars at the top of each graph represents the light (day) and dark (night) periods, respectively. The actogram is double-plotted for better visualization. 
After 17:00h, in anticipation of the nocturnal phase, an increase of activity was observed, probably related to closure of the research station and the absence of anthropogenic disturbance. The application of the COSINOR analysis revealed a significant daily rhythm $(p<0.0001)$, with a mesor of 4.76 counts $/ 10 \mathrm{~min}$, amplitude of 2.76 counts $/ 10 \mathrm{~min}$ and an acrophase located at 01:09 $\mathrm{h}$, as depicted in the Polar representation of the COSINOR analysis (Figure 3c).

During autumn, despite the temperature drop (averaged at $18.4 \pm 3.4^{\circ} \mathrm{C}$, Figure 2), such behaviour was maintained (Figure 4), but lower levels of activity were verified. Once again, there was a clear preference of cuttlefish for being active during night time (Figure $4 a, b)$, with $33.88 \%$ and $66.12 \%$ of activity ( $0.95 \pm 0.69$ and $1.49 \pm 0.66$ counts $/ 10 \mathrm{~min})$, respectively, for day and night periods $(p<0.001)$. The COSINOR analysis confirmed the significance of the rhythm $(p<0.01)$, with a mesor of 1.28 counts $/ 10^{\prime} \mathrm{min}$, an amplitude of 0.27 counts $/ 10 \mathrm{~min}$ and an acrophase located at $21: 47 \mathrm{~h}$ (Figure $4 \mathrm{c}$ ). Such acrophase change from summer to autumn $(01: 09 \mathrm{~h}$ to $21: 47 \mathrm{~h})$ is very likely to be related to sunset time. In fact, considering that in summer the sunset was around 20:00 h, and in autumn at 17:30 h, the acrophase occurred respectively 5 and $4 \mathrm{~h}$ after, reinforcing the idea of a strong synchronization of behaviour with the daily photoperiod cycle. Furthermore, the activity peaks seen, associated with feeding times, also reveal a synchronization role of this factor.

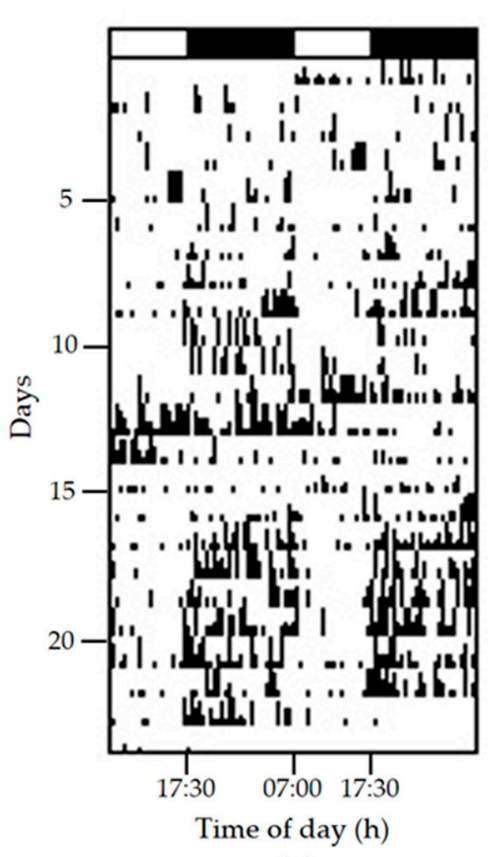

(a)

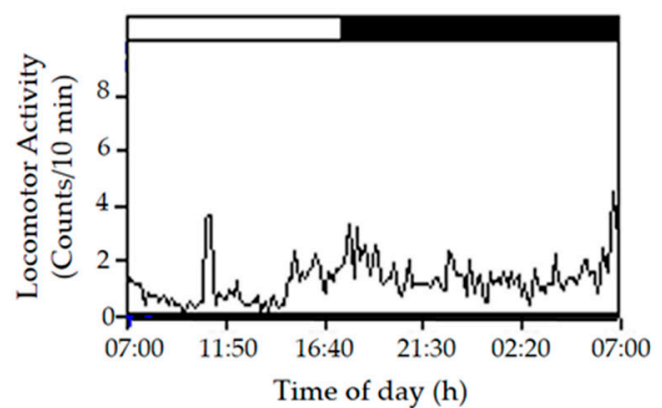

(b)

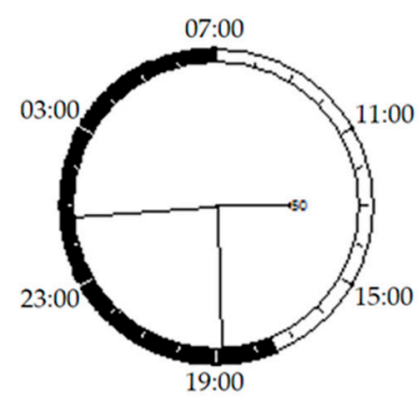

(c)

Figure 4. Representative actogram of locomotor activity of cuttlefish reared under natural conditions of photoperiod (11:13 LD), registered during autumn (a) and respective mean waveform (b) and polar representation of the COSINOR analysis, depicting clockwise the daily cycle of activity (c). The white and black bars at the top of each graph represents the light (day) and dark (night) periods, respectively. The actogram is double-plotted for better visualization.

Sepia officinalis has been reported to possess a diurnal feeding rhythm in the natural environment not regulated by lunar cycles, persisting in different moments of the annual cycle, with feeding activity occurring essentially in twilight periods [23], in accordance with the nocturnal behaviour in summer and autumn observed in the present study. Since these animals where hatched from wild eggs, it should not be surprising that they present a similar behaviour to that of wild animals. Denton and Gilpin-Brown [22] had previously identified daily rhythms of activity in this species, associated with changes in cuttlebone density regulated by light. In darkness, the density decreases and the cuttlefish becomes more buoyant, 
acquiring a larger movement capacity and a higher rate of success in capturing prey. Moreover, cuttlefish are known to use polarization sensitivity during predation as well as intraspecific recognition and communication [24-26]. In line with such rhythms of activity, Jäckel et al. [27] observed daily oscillations in metabolic rates, with 30-40\% rise in oxygen consumption after sunset. In agreement are the sleep-like states established by Frank et al. [11], which also follow a rhythmic pattern, with ca. $80 \%$ of resting time occurring during daytime, where their vision is affected by UV radiation [28]. All the above evidence, along with the present results, reinforce the rhythmic fashion of this species behaviour and physiology, with a preference of cuttlefish for being nocturnal in summer and in autumn. Other cephalopod species, such as Eledone cirrhosa [6] or Octopus macropus [9], also showed a nocturnal pattern, and have polarized vision $[29,30]$, while for O. vulgaris results seemed to be inconsistent [8,9]. Such differences among cephalopod species might reflect their lifestyles in the natural environment, with the nocturnal behaviour being a clear advantage for predation. However, comparisons should be made with caution since not all studies mention the season when the tests were conducted, nor the temperatures associated. In winter, when temperature lowered to values of $12.7 \pm 1.4{ }^{\circ} \mathrm{C}$, the daily rhythm changed, with the highest levels of activity now being registered during the afternoon (Figure 5). For this data sub-set, two different patterns were identified (Figure 5a): one in December and another in January. In December (13.8 $\pm 1.1^{\circ} \mathrm{C}$, Figure 2), high levels of activity were registered during both day and night periods, related with reproductive behaviour and spawning events (data not shown). However, when data were plotted as a mean waveform (Figure $5 b$ ), a clear peak of activity could be observed in the middle of the day period (13:10 h). In this month, $47.06 \%$ of the total activity was registered during the day, while $52.94 \%$ occurred during the night. Although both percentages were very close to $50 \%$, daytime activity was shown to be significantly higher than the one registered during the night (mean values $21.69 \pm 6.14$ and $16.94 \pm 1.66$ counts $/ 10 \mathrm{~min}$ respectively, $p<0.001$ ).

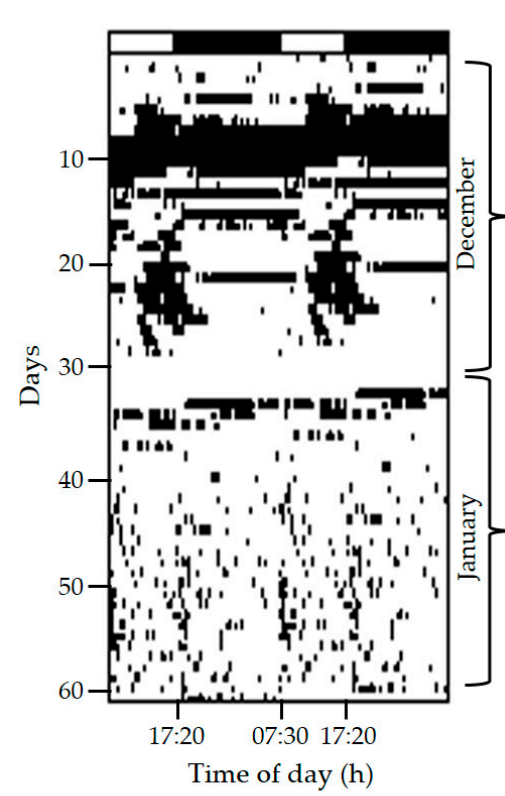

(a)

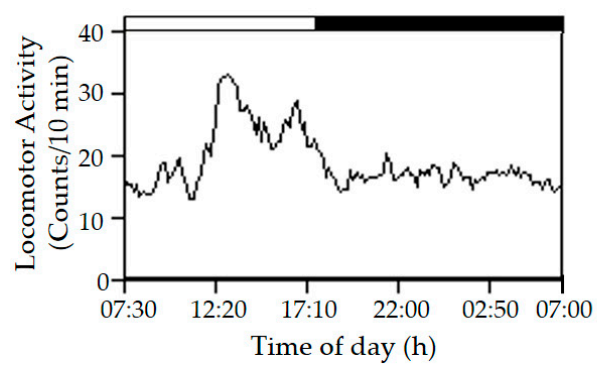

(b)

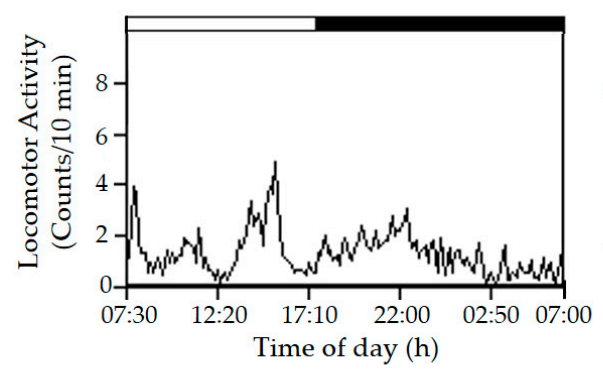

(d)
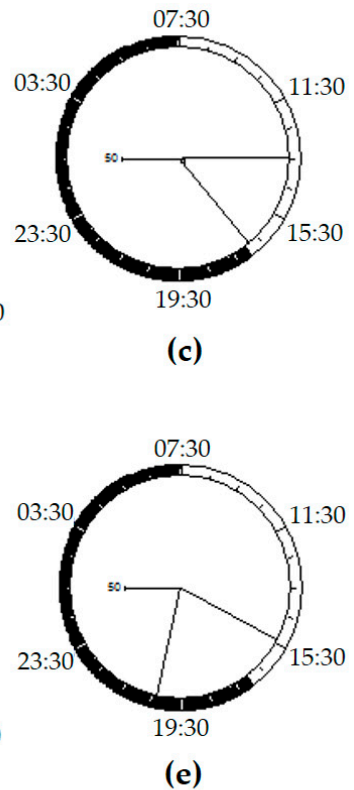

(e)

Figure 5. Representative actogram of locomotor activity of cuttlefish reared under natural conditions of photoperiod (10:14 LD) during winter (a) and corresponding analysis for the periods of December and January: mean waveform (b) and polar representation of the COSINOR analysis (c) for December and mean waveform (d) and COSINOR analysis (e) for January. The white and black bars at the top of each graph show the light (day) and dark (night) periods respectively. The actogram is double-plotted for better visualization. 
During January $\left(13.1 \pm 0.8^{\circ} \mathrm{C}\right.$, Figure 2$)$, the levels of activity decreased greatly (Figure 5a), and the daily pattern was not so clear. The mean waveform (Figure $5 \mathrm{~d}$ ) showed a clear activity peak in late afternoon $(15: 40 \mathrm{~h})$, however the locomotor activity did not show significant differences between day (1.45 $1.03 \pm$ counts $/ 10 \mathrm{~min}, 45.74 \%)$ and night $(1.21 \pm 0.65$ counts $/ 10 \mathrm{~min}, 54.26 \%)$ periods $(p>0.05)$, thus being considered arrhythmic for this period. Such accented decrease in activity could be either related with the low temperatures registered or with the decrease in number of animals associated with the mortality registered short after reproduction in these tanks [31]. The COSINOR analysis for the winter period was applied separately for each of these time intervals, and in both cases the rhythm was confirmed to be significant $(p<0.001)$ : mesor of 18.90 and 1.31 counts $/ 10 \mathrm{~min}$, amplitude of 4.27 and 0.41 counts $/ 10 \mathrm{~min}$ and acrophases at 15:20 h and 18:13 h, respectively for December and January (Figure 5c,e).

As with the photoperiod, temperature is also known to be a strong modulator of rhythms in aquatic animals, especially for ectothermic animals [20] like cuttlefish [32]. Indeed, the present results showed an accented decrease in activity along with the temperature drop (with the exception of the reproduction period in December), suggesting an important role of temperature in the synchronization of this species' behaviour rhythms, as verified for the photoperiod.

Cuttlefish showed a clear preference for being active during the night in summer and in autumn, while in winter this preference changed, with higher levels of activity observed during the afternoon, revealing a high plasticity of the circadian system of this species [19], and resembling a dualistic behaviour, which according to Eriksson [33], is "the ability to shift behavioural patterns and change from diurnal to nocturnal and vice versa at some stages of life history". To the best of our knowledge, no similar evidence has been observed in cephalopods, however several fish species and the oyster Crassostrea gigas [34] have been described as possessing such capacity. One of the most common examples is the European sea bass Dicentrarchus labrax, which exhibited such behaviour in feeding patterns, under both natural [35] and controlled laboratorial conditions [36,37], being predominantly diurnal in summer, nocturnal in winter and then returning to diurnal behaviour in spring $[36,38]$. The cuttlefish seemed to present a similar behaviour in terms of locomotor activity, being very likely a dual species.

\section{Materials and Methods}

\subsection{Ethical Statement}

This experiment was performed under Projects SEPIABREED (FCT PTDC/MAR/120876/2010), SEPIATECH (PROMAR 31.03.05.FEP.002) and SEPIAMETA (FCT PTDC/MAR/102348/2008), which were approved before the entry into force of Directive 2010/63/EU [39] as national legislation in Portugal. Nonetheless, the present experiment did not cross the threshold set for regulation (i.e., procedures that may cause pain, suffering, distress or lasting harm equivalent to or higher than that caused by the insertion of a hypodermic needle in line with good veterinary practice). Also, ethics for biological rhythm research [40] were considered, and the cuttlefish involved in the present study were reared according to the best practice described by Sykes et al. [41] and Fiorito et al. [10].

\subsection{Experimental Design}

The present study was performed over 7 months (213 days) in 2011-2012 at the Centro de Ciências do Mar (CCMAR) Ramalhete Aquaculture Station (Ria Formosa, South Portugal-37 $00^{\prime} 22.39^{\prime \prime} \mathrm{N}$; $\left.7^{\circ} 58^{\prime} 02.69^{\prime \prime} \mathrm{W}\right)$. All cuttlefish hatched from eggs collected in the wild. The embryonic development of eggs, as well as hatchlings and juvenile's rearing, was performed according to the technology described by Sykes et al. [41]. Two groups of 20 cuttlefish juveniles ( $56.5 \pm 17.8 \mathrm{~g}$; with an age of 75 days after hatching) were reared until natural death (133.6 $\pm 59.4 \mathrm{~g}$; and showing sex ratios of 1:1) in two $500 \mathrm{~L}$ rectangular outdoor tanks (with a bottom area of $1.0 \times 1.0 \mathrm{~m}$ ) provided with a constant seawater flow in an open system. These tanks were set up and covered with a green net, to diminish light 
intensity. Parameters of water quality, such as temperature, dissolved oxygen saturation and salinity were monitored daily with an Oxiguard Handy probe and a VWR EC300 salinity meter. Environmental parameters oscillated naturally, on a daily basis and throughout the seven months of the study. Overall mean temperature was $17.9 \pm 5.0^{\circ} \mathrm{C}$ (range of $27.4-8.9^{\circ} \mathrm{C}$ ), salinity was $35.1 \pm 1.7 \mathrm{~g} \cdot \mathrm{L}^{-1}$ (range of 37.6-30.2 $\mathrm{g} \cdot \mathrm{L}^{-1}$ ) and dissolved oxygen concentration was $100.3 \pm 4.6 \%$ saturation (range of $88-110 \%$ ). Animals were fed twice a day ad libitum with frozen grass shrimp Palaemonetes varians at $10 \mathrm{~h}$ and $16 \mathrm{~h}$. Mean cumulative mortality (\%) was determined daily.

In order to characterize this species chronotype, locomotor activity was monitored from August 2011 until February 2012 (across three different seasons). For the registration of locomotor activity, one photocell (E3S-AD62, OMRON, Kioto, Japan) was installed inside each tank (at mid water height $-26 \mathrm{~cm}$ ), connected to a motherboard (USB-1024HLS, Measurement Computing, Norton, MA, USA) which, in turn, was connected to a computer (Benq T2210HD). Every time a cuttlefish interrupted the infrared light beam (ca. $20 \mathrm{~cm}$ ), an output signal was produced, which was recorded and stored in 10 min bins using specialized software (DIO98USB, University of Murcia, Murcia, Spain).

\subsection{Data Analysis}

Since data was expected to vary throughout the year, sub-sets were analysed separately (coinciding with seasons) [42], considering temperature and photoperiod natural oscillations (Figure 2). To avoid bias from a low number of individuals in the tanks due to natural mortality, this analysis ended when $80 \%$ of cuttlefish of each tank died (31/01/2012). In order to identify rhythm patterns for each data sub-set, activity records were plotted in the form of actograms and mean waveforms using the software El Temps (University of Barcelona, Barcelona, Spain; A. Diez-Noguera), representing, respectively, the locomotor activity along successive day cycles double-plotted on successive horizontal lines, and the mean activity along the $24 \mathrm{~h}$ cycle. Cuttlefish were either categorized as diurnal or nocturnal, depending on when (i.e., day or night, respectively) locomotor activity presented major values. All data was tested for normal distribution using the Shapiro-Wilk test [43]. Significant differences between mean diurnal and nocturnal activity counts were evaluated through a paired Student's $t$-test. Statistical difference was considered for $p<0.01$. When no statistical differences between diurnal and nocturnal activity means were observed for a certain data sub-set, the animals were considered arrhythmic [44].

Statistical significance of activity daily rhythms was tested using a COSINOR analysis $[45,46]$. The 'amplitude' (one-half the peak-to-trough variation), 'mesor' (the time series mean), and 'acrophase' (peak time relative to the time scale) were determined by the least-squares approximation of cosine function.

\section{Conclusions}

In summary, S. officinalis has been observed as a nocturnal species during summer and autumn, turning to diurnal in December and becoming arrhythmic in January, in close relationship with the main environmental synchronizers: photoperiod determining the activity periods, and temperature modulating the levels of activity. Due to such observed capacity to change behaviour along the year, it has even been suggested to be a dual species. Such data is an added value for this species adaptation to aquaculture conditions, allowing the improvement of all kinds of culture husbandry protocols; e.g., knowing when this species is active during the $24 \mathrm{~h}$ of the day and at different seasons might help optimize handling, feeding and breeding protocols, and consequently this species' welfare under captive conditions.

Acknowledgments: The authors would like to thank João Reis, from Ramalhete Experimental Station, for the help with photocells settlement. This study was funded by Fundação para a Ciência e a Tecnologia (FCT) (SEPIAMETA-PTDC/MAR/102348/2008) and SEPIABREED (PTDC/MAR/120876/2010), FP7 program (ProSpawn-FP7/SME/2008/1), EC (ASSEMBLE-EC/FP7/227799) and PROMAR program (SEPIATECH-31-03-05-FEP-2); and FCT grants to C.C.V.O. (SFRH/BPD/63933/2009) and A.V.S. (SFRH/BPD/36100/2007; Investigador FCT contract IF/00576/2014) and a grant from the FP7 project COPEWELL (265957) to M.I.G.-M. 
Author Contributions: C.C.V.O. and A.V.S. were responsible for the design and supervision of the study, carried out data analysis and respective interpretation of results and made major contributions to the manuscript. R.A.G. and P.A.F. carried out the setup of the experiment, were responsible for the maintenance of the animals, and for data collection. M.I.G.-M. drafted the manuscript, contributed to the figure analysis and was involved in revising the manuscript. All authors have read and approved the final manuscript.

Conflicts of Interest: The authors declare no conflict of interest. The founding sponsors had no role in the design of the study; in the collection, analyses, or interpretation of data; in the writing of the manuscript, and in the decision to publish the results.

\section{References}

1. Barnabé, G. Bases Biologiques et Écologiques de L'aquaculture; Editorial Acribia, S.A.: Zaragoza, Spain, 1996; p. 519.

2. Iglesias, J.; Fuentes, L.; Villanueva, R. Cephalopod Culture; Springer: Dordrecht, The Netherlands, $2014 ;$ p. 494.

3. Villanueva, R.; Sykes, A.V.; Vidal, É.A.G.; Rosas, C.; Nabhitabhata, J.; Fuentes, L.; Iglesias, J. Current status and future challenges in cephalopod culture. In Cephalopod Culture; Iglesias, J., Fuentes, L., Villanueva, R., Eds.; Springer: Dordrecht, The Netherlands, 2014; pp. 479-489.

4. Sykes, A.V.; Koueta, N.; Rosas, C. Historical review of cephalopods culture. In Cephalopod Culture; Iglesias, J., Fuentes, L., Villanueva, R., Eds.; Springer: Dordrecht, The Netherlands, 2014; pp. 59-75.

5. Fiorito, G.; Affuso, A.; Anderson, D.B.; Basil, J.; Bonnaud, L.; Botta, G.; Cole, A.; D’Angelo, L.; De Girolamo, P.; Dennison, N.; et al. Cephalopods in neuroscience: Regulations, research and the 3rs. Invertebr. Neurosci. 2014, 14, 13-36. [CrossRef] [PubMed]

6. Cobb, C.S.; Pope, S.K.; Williamson, R. Circadian rhythms to light-dark cycles in the lesser octopus, Eledone cirrhosa. Mar. Freshw. Behav. Physiol. 1995, 26, 47-57. [CrossRef]

7. Cobb, C.S.; Williamson, R.; Pope, S.K. The responses of the epistellar photoreceptors to light and their effecyt on circadian rhythms in the lesser octopus, Eledone cirrhosa. Mar. Freshw. Behav. Physiol. 1995, 26, 59-69. [CrossRef]

8. Meisel, D.V.; Byrne, R.A.; Kuba, M.; Griebel, U.; Mather, J.A. Circadian rhythms in Octopus vulgaris. Berliner Paläobiol. Abh. 2003, 3, 171-177.

9. Meisel, D.V.; Byrne, R.A.; Kuba, M.; Mather, J.; Ploberger, W.; Reschenhofer, E. Contrasting activity patterns of two related octopus species, Octopus macropus and Octopus vulgaris. J. Comp. Psychol. 2006, 120, 191-197. [CrossRef] [PubMed]

10. Fiorito, G.; Affuso, A.; Basil, J.; Cole, A.; de Girolamo, P.; D’Angelo, L.; Dickel, L.; Gestal, C.; Grasso, F.; Kuba, M.; et al. Guidelines for the care and welfare of cephalopods in research-A consensus based on an initiative by cephres, felasa and the boyd group. Lab. Anim. 2015, 49, 1-90. [CrossRef] [PubMed]

11. Frank, M.G.; Waldrop, R.H.; Dumoulin, M.; Aton, S.; Boal, J.G. A preliminary analysis of sleep-like states in the cuttlefish sepia officinalis. PLoS ONE 2012, 7, e38125. [CrossRef] [PubMed]

12. Dunlap, J.C.; Loros, J.J.; DeCoursey, P.J. Chronobiology: Biological Timekeeping; Sinauer Associates Inc.: Sunderland, MA, USA, 2004.

13. Bernier, N.J.; Van Der Kraak, G.; Farrell, A.P.; Brauner, C.J. Fish Neuroendocrinology, 1st ed.; Academic Press: London, UK, 2009; Volume 28.

14. Cermakian, N.; Sassone-Corsi, P. Environmental stimulus perception and control of circadian clocks. Curr. Opin. Neurobiol. 2002, 12, 359-365. [CrossRef]

15. Oliveira, C.; Sánchez-Vázquez, F.J. Reproduction rhythms in fish. In Biological Clock in Fish; Kulczykowska, E., Popek, W., Kapoor, B., Eds.; Science Publishers: Enfield, NH, USA, 2010; pp. 185-215.

16. López-Olmeda, J.F.; Sánchez-Vázquez, F.J. Feeding rhythms in fish: From behavioural to molecular approach. In Biological Clock in Fish; Kulczykowska, E., Popek, W., Kapoor, B., Eds.; Science Publishers: Enfield, NH, USA, 2010; pp. 155-184.

17. Pardini, L.; Kaeffer, B. Feeding and circadian clocks. Reprod. Nutr. Dev. 2006, 46, 463-480. [CrossRef] [PubMed]

18. Sánchez-Vázquez, F.J.; Madrid, J.A.; Zamora, S.; Tabata, M. Feeding entrainment of locomotor activity rhythms in the goldfish is mediated by a feeding-entrainable circadian oscillator. J. Comp. Physiol. A 1997, 181, 121-132. [CrossRef] 
19. Reebs, S.G. Plasticity of diel and circadian activity rhythms in fishes. Rev. Fish Biol. Fish. 2002, 12, 349-371. [CrossRef]

20. López-Olmeda, J.F. Nonphotic entrainment in fish. Comp. Biochem. Physiol. A 2017, 203, 133-143. [CrossRef] [PubMed]

21. Hanlon, R.T.; Messenger, J.B. Cephalopod Behavior; Cambridge University Press: New York, NY, USA, 1996; p. 232.

22. Denton, E.J.; Gilpin-Brown, J.B. The effect of light on the buoyancy of the cuttlefish. J. Mar. Biol. Assoc. UK 1961, 41, 343-350. [CrossRef]

23. Quintela, J.; Andrade, J.P. Diel feeding rhythms, daily ration and gastric evacuation rates of Sepia officinalis in the Ria Formosa Lagoon (south Portugal). Bull. Mar. Sci. 2002, 71, 665-680.

24. Shashar, N.; Rutledge, P.S.; Cronin, T.W. Polarization vision in cuttlefish-A concealed communication channel? J. Exp. Biol. 1996, 199, 2077-2084. [PubMed]

25. Shashar, N.; Hanlon, R.T.; Petz, A.D.M. Polarization vision helps detect transparent prey. Nature 1998, 393, 222-223. [CrossRef]

26. Shashar, N.; Hagan, R.; Boal, J.G.; Hanlon, R.T. Cuttlefish use polarization sensitivity in predation on silvery fish. Vis. Res. 2000, 40, 71-75. [CrossRef]

27. Jäckel, G.; Mark, F.; Gutowska, M.; Claireaux, G.; Ellington, C.; Pörtner, H. Analysis of Diurnal Activity Patterns and Related Changes in Metabolism in the Cephalopod Sepia officinalis. In Annual Main Meeting of the Society for Experimental Biology; Comparative Biochemistry and Physiology: Glasgow, Scotland, 2007; Volume 146A, p. S83.

28. Shashar, N.; Harosi, F.I.; Banaszak, A.T.; Hanlon, R.T. UV radiation blocking compounds in the eye of the cuttlefish Sepia officinalis. Biol. Bull. 1998, 195, 187-188. [CrossRef] [PubMed]

29. Shashar, N.; Cronin, T.W. Polarization contrast vision in Octopus. J. Exp. Biol. 1996, 199, 999-1004. [PubMed]

30. Shashar, N.; Hanlon, R.T. Squids (Loligo pealei and Euprymna scolopes) can exhibit polarized light patterns produced by their skin. Biol. Bull. 1997, 193, 207-208. [CrossRef] [PubMed]

31. Guerra, A.; Robin, J.P.; Sykes, A.V.; Koutsoubas, D.; Jereb, P.; Lefkaditou, E.; Koueta, N.; Allcock, A. Sepia officinalis. In Cephalopod Biology and Fisheries in Europe; Jereb, P., Allcock, A., Lefkaditou, E., Piatkowski, U., Hastie, L.C., Pierce, G.J., Eds.; ICES Cooperative Research Report 325; International Council for the Exploration of the Sea: Copenhagen, Denmark, 2015; Volume II, Species Accounts; pp. 53-73.

32. Zielinski, S.; Portner, H.O. Oxidative stress and antioxidative defense in cephalopods: A function of metabolic rate or age? Comp. Biochem. Physiol. B 2000, 125, 147-160. [CrossRef]

33. Eriksson, L. Nocturnalism versus diurnalism: Dualism within fish individuals. In Rhythmic Activity of Fishes; Thorpe, J.E., Ed.; Academic Press: New York, NY, USA, 1978; pp. 69-89.

34. Mat, A.M.; Massabuau, J.-C.; Ciret, P.; Tran, D. Evidence for a plastic dual circadian rhythm in the oyster Crassostrea gigas. Chronobiol. Int. 2012, 29, 857-867. [CrossRef] [PubMed]

35. Anras, M.-L.B. Demand-feeding behaviour of sea bass kept in ponds: Diel and seasonal patterns, and influences of environmental factors. Aquac. Int. 1995, 3, 186-195. [CrossRef]

36. Sanchez-Vázquez, F.J.; Madrid, J.A.; Zamora, S. Circadian rhythms of feeding activity in sea bass, Dicentrarchus labrax L.: Dual phasing capacity of diel demand-feeding pattern. J. Biol. Rhythms 1995, 10, 256-266. [CrossRef] [PubMed]

37. Aranda, A.; Sánchez-Vázquez, F.J.; Madrid, J.A. Influence of water temperature on demand-feeding rhythms in sea bass. J. Fish Biol. 1999, 55, 1029-1039. [CrossRef]

38. Sanchez-Vazquez, F.J.; Azzaydi, M.; Martinez, F.J.; Zamora, S.; Madrid, J.A. Annual rhythms of demand-feeding activity in sea bass: Evidence of a seasonal phase inversion of the diel feeding pattern. Chronobiol. Int. 1998, 15, 607-622. [CrossRef] [PubMed]

39. Eurropean Union (EU). Directive 2010/63/EU of the European Parliament and of the Council of 22 September 2010 on the Protection of Animals Used for Scientific Purposes, EN ed.; Union, E., Ed.; Official Journal of European Union: Brussels, Belgium, 2010; Volume L276, pp. 33-79.

40. Portaluppi, F.; Smolensky, M.H.; Touitou, Y. Ethics and methods for biological rhythm research on animals and human beings. Chronobiol. Int. 2010, 27, 1911-1929. [CrossRef] [PubMed]

41. Sykes, A.V.; Domingues, P.; Andrade, J.P. Sepia officinalis. In Cephalopod Culture; Iglesias, J., Fuentes, L., Villanueva, R., Eds.; Springer: Dordrecht, The Netherlands, 2014; pp. 175-204. 
42. Díez-Noguera, A. Methods for serial analysis of long time series in the study of biological rhythms. J. Circadian Rhythms 2013, 11, 7. [CrossRef] [PubMed]

43. Zar, J.H. Biostatistical Analysis, 4th ed.; Prentice-Hall Inc.: Upper Saddle River, NJ, USA, 1999.

44. Vera, L.M.; Cairns, L.; Sánchez-Vázquez, FJ.; Migaud, H. Circadian rhythms of locomotor activity in the nile tilapia Oreochromis niloticus. Chronobiol. Int. 2009, 26, 666-681. [CrossRef] [PubMed]

45. Díez, A. Representación gráfica y análisis de datos en cronobiología. In Cronobiología Básica y Clínica; Madrid, J.A., Rol de Lama, M.A., Eds.; Editec@red S.L.: Madrid, Spain, 2007; pp. 84-121.

46. Cornelissen, G. Cosinor-based rhythmometry. Theor. Biol. Med. Model. 2014, 11, 16. [CrossRef] [PubMed]

(C) 2017 by the authors. Licensee MDPI, Basel, Switzerland. This article is an open access article distributed under the terms and conditions of the Creative Commons Attribution (CC BY) license (http:/ / creativecommons.org/licenses/by/4.0/). 